\title{
Spinal Epidural Cavernous Hemangioma of the Thoracic Spine: A Case Report
}

\author{
Ryoichi Fukano1, Yasuaki Iida1, Keiji Hasegawa1, Yuichirou Yokoyama1, Akihito Wada1, \\ Shigeta Takeuchi', Kazutoshi Shibuya ${ }^{2}$, Hiroshi Takahashi ${ }^{1}$ \\ ${ }^{1}$ Department of Orthopaedic Surgery, Toho University School of Medicine, Tokyo, Japan \\ ${ }^{2}$ Department of Pathology, Toho University School of Medicine, Tokyo, Japan \\ Email: drkan@med.toho-u.ac.jp
}

Received 14 September 2015; accepted 17 October 2015; published 20 October 2015

Copyright (C) 2015 by authors and Scientific Research Publishing Inc.

This work is licensed under the Creative Commons Attribution International License (CC BY). http://creativecommons.org/licenses/by/4.0/

(c) (7) Open Access

\begin{abstract}
Cavernous hemangiomas can arise in any region of the body, including the central nervous system. Spinal cavernous hemangiomas account for $5 \%-12 \%$ of all cases of vertebral vascular malformation. Most of these are of vertebral origin, and cases that are non-vertebral in origin are rare. We encountered a patient with a relatively rare spinal epidural cavernous hemangioma of the thoracic spine that was non-vertebral in origin. The patient was a 63-year-old man. He had become aware of bilateral leg pain and numbness about 2 months earlier, and gait disturbance appeared gradually thereafter. On MRI, a lesion showing iso-intensity on T1-weighted imaging and high intensity on T2-weighted imaging was detected at the $7^{\text {th }}$ thoracic vertebra. On gadolinium contrast-imaging, the lesion was found to be a homogenously-enhanced dumbbell-shaped extradural spinal neoplasm protruding from the left $7^{\text {th }} / 8^{\text {th }}$ thoracic intervertebral foramen. A neurogenic tumor was suspected based on myelography and MRI findings, and complete tumorectomy was performed, which improved the lower limb symptoms and gait disturbance. The histopathological diagnosis was cavernous hemangioma. Epidural hemangiomas arise from the vertebra in many cases, and pure spinal epidural cavernous hemangiomas are rare. It is difficult to make a preoperative diagnosis because there are no specific imaging findings that can differentiate these tumors. It may be important to consider this disease before surgery in the differential diagnosis of epidural tumors.
\end{abstract}

\section{Keywords}

Epidural Cavernous Hemangioma, Thoracic Spine, Myelopathy

\section{Introduction}

Cavernous hemangiomas may develop in any region in the human body, and many cases of spinal epidural ca-

How to cite this paper: Fukano, R., lida, Y., Hasegawa, K., Yokoyama, Y., Wada, A., Takeuchi, S., Shibuya, K. and Takahashi, H. (2015) Spinal Epidural Cavernous Hemangioma of the Thoracic Spine: A Case Report. Open Journal of Orthopedics, 5, 311-318. http://dx.doi.org/10.4236/ojo.2015.510042 
vernous hemangiomas arising from the vertebrae have been reported [1]. While expansion of cavernous hemangiomas of vertebral origin into the epidural space has also been reported occasionally, cavernous hemangiomas of purely spinal epidural origin are rare [2]. With respect to the differential diagnosis, there are no characteristic physical or imaging findings for such epidural tumors. Thus, it is difficult to make a definite diagnosis before surgery, due to the low incidence and the absence of characteristic imaging findings. We encountered a patient who developed spinal cord symptoms associated with spinal epidural cavernous hemangioma arising from outside the vertebra.

We report the case with a review of the literature.

\section{Case Presentation}

The patient was a 63-year-old man who had developed bilateral leg pain and numbness about 2 months earlier, with the subsequent gradual onset of gait disturbance. When he visited a physician, MRI findings suggested a spinal cord tumor at the $7^{\text {th }}$ thoracic vertebral level. Thus, the patient was referred to our department. During the first examination, left-side dominant pain was noted in the bilateral thighs over the medial crura, but there was no tenderness or knocking pain in the dorsal region. No sensory disturbance was observed, and the bilateral lower limb muscle strength was normal. The patellar and Achilles tendon reflexes were enhanced on the left side, but no morbid reflex was observed, nor were there any bladder or rectal disturbances.

On chest plain radiography, there were no abnormal findings. Plain MRI demonstrated a dumbbell-shaped tumor protruding from the left $7^{\text {th }} / 8^{\text {th }}$ thoracic intervertebral foramen, and a spinal epidural lesion with intensity equivalent to that of the spinal cord on T1-weighted imaging and high intensity on T2-weighted imaging. On gadolinium-contrast imaging, the lesion was mostly homogenously enhanced (Figure 1). On myelography, the dural canal was excluded by an extramedullary tumor at the $7^{\text {th }}$ thoracic vertebra (Figure 2). Schwannoma was suspected based on these findings, and complete tumorectomy was planned. When laminectomy was applied to the $7^{\text {th }}$ thoracic vertebra, a lesion that occupied about half the circumferential space was noted in the left dorsal dura mater over the lateral side, and a dark reddish elastic soft mass with abundant blood vessels was present. To observe the entire mass, the left T7 inferior articular process was resected and the dumbbell-shaped mass was confirmed. Since the mass and nerve root were strongly adherent, the nerve root was ligated and transected and the mass was excised. After excision of the mass, bulging and pulsation of the dural canal appeared favorable (Figure 3). Histopathological examination showed many blood vessels of various sizes and a thin fibrous or smooth muscular wall. Some of these blood vessels were accompanied by organized thrombi in the lumen, and the mass was diagnosed as a cavernous hemangioma (Figure 4).

As of one year after surgery, no neurological findings have been observed, and the gait disturbance has improved. No recurrence has been observed on MRI, and the course has remained favorable (Figure 5).

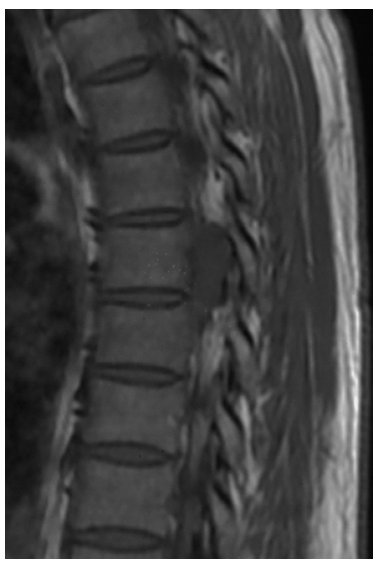

(a)

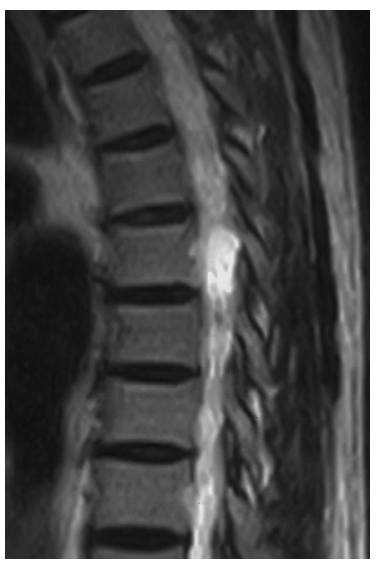

(b)

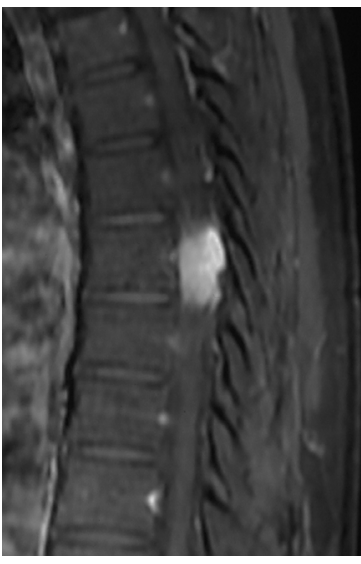

(c)

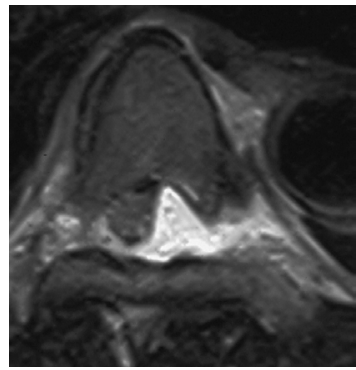

(d)

Figure 1. Thoracic spine MRI before operation. A space occupying lesion was evident showing iso-intensity on the T1 weighted image and high intensity on the T2 weighted image that was enhanced with gadolinium-contrast imaging. The tumor was dumbbell-shaped, protruding from the left $7^{\text {th }} / 8^{\text {th }}$ thoracic intervertebral foramen. (a) Sagittal T1 WI; (b) Sagittal T2 WI; (c) Sagittal Gd-DTPA; (d) Axial T2 WI. 


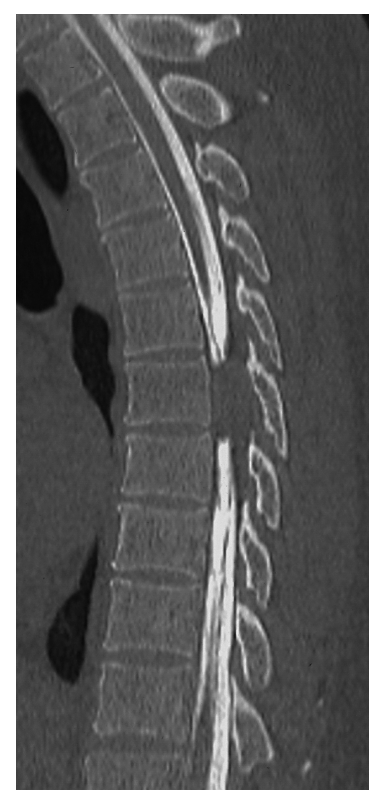

(a)

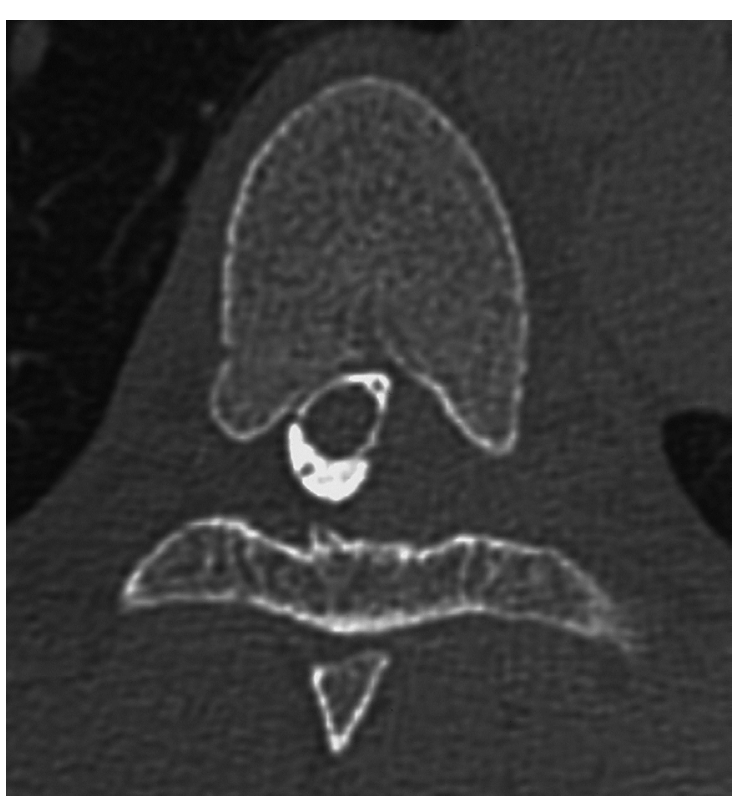

(b)

Figure 2. CT myelographm. (a) Sagittal reconstruction CT after myelogram; (b) Axial CT after myelogram.

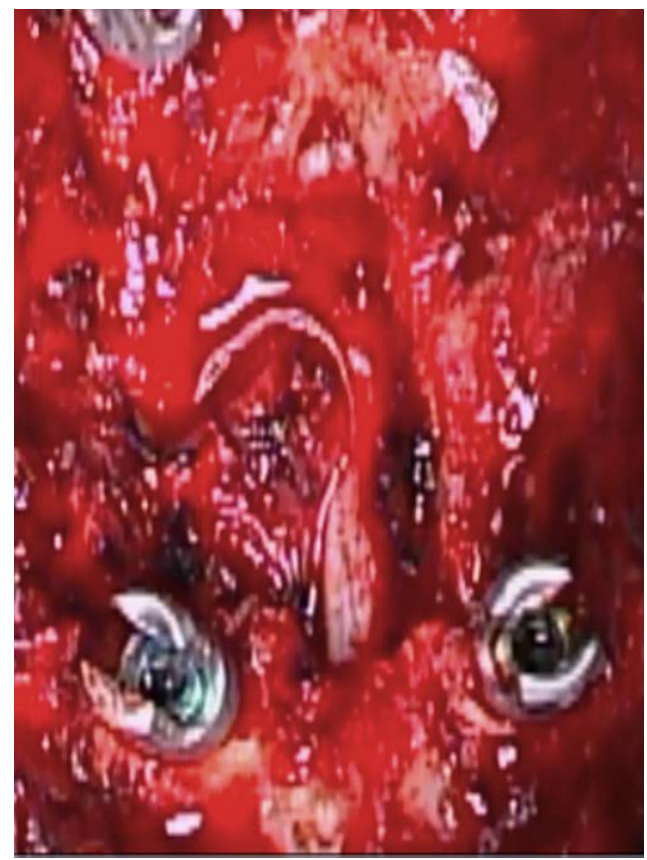

(a)

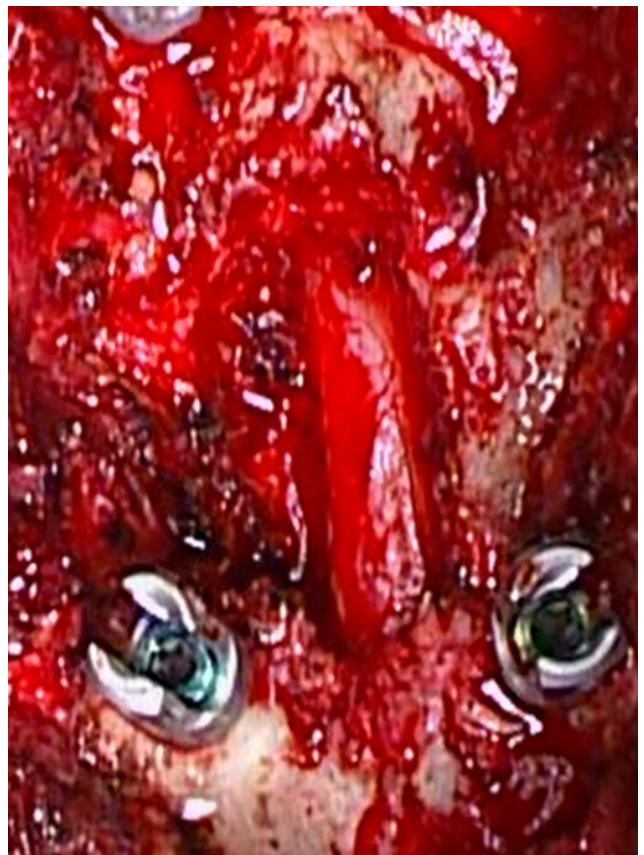

(b)

Figure 3. Intraoperative findings. (a) A dark reddish elastic soft mass with abundant blood vessels was present in the dorsal dura mater over the lateral side; (b) After excision of the mass, bulging and pulsation of the dural canal appeared favorable.

\section{Discussion}

Cavernous hemangiomas can arise in any region of the body, including the central nervous system. Epidemiologically, according to Hillman et al. [1], about 220,000 people worldwide develop cavernous hemangiomas annually, and cases of vertebral origin are relatively rare. Spinal cavernous hemangiomas account for 5\% - 12\% of all cases of vertebral vascular malformation. While most cases are of vertebral origin, cases of extravertebral origin account for only $0.4 \%$ [2]-[4]. Epidural cavernous hemangiomas account for about $4 \%$ of all spinal epidural 


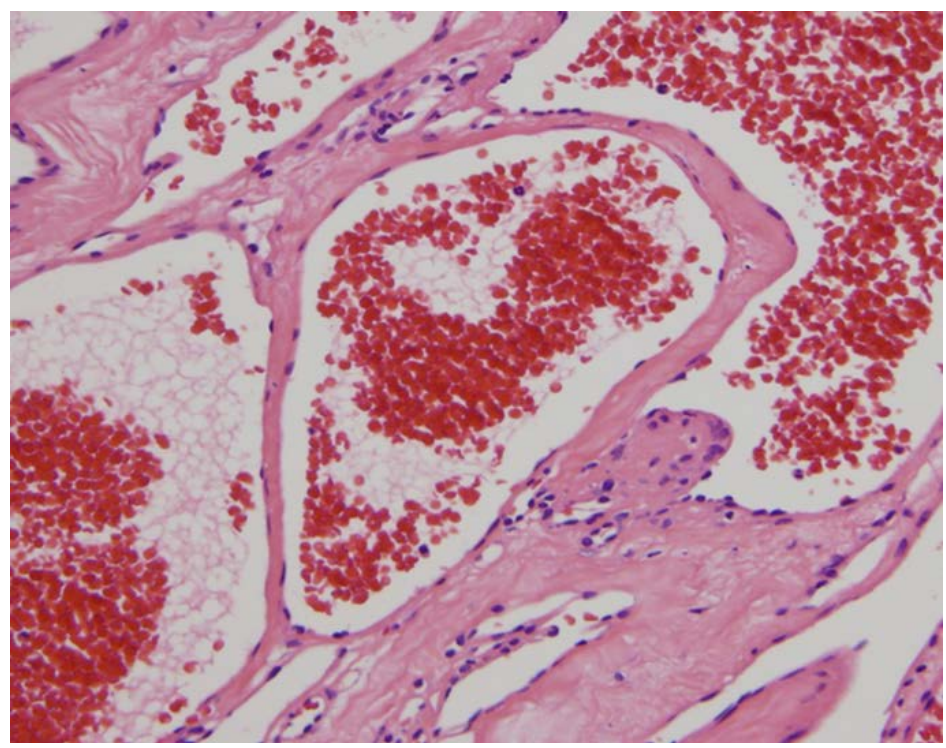

Figure 4. Histological examination showed many vessels of various sizes and a thin fibrous or smooth muscular wall. Some of these blood vessels were accompanied by organized thrombi within the lumen (Hematoxylin and eosin $100 \times$ ).

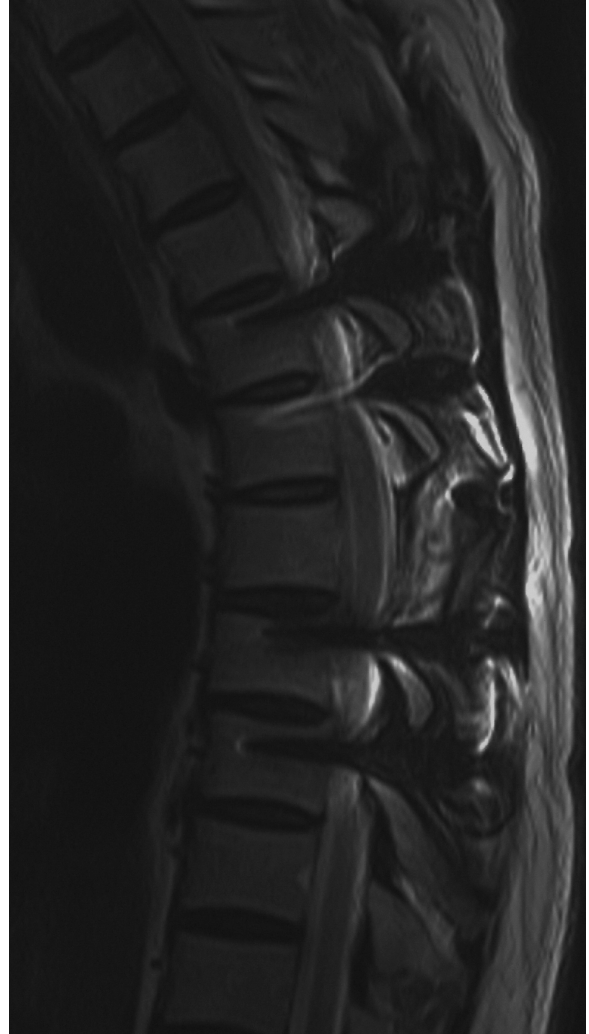

(a)

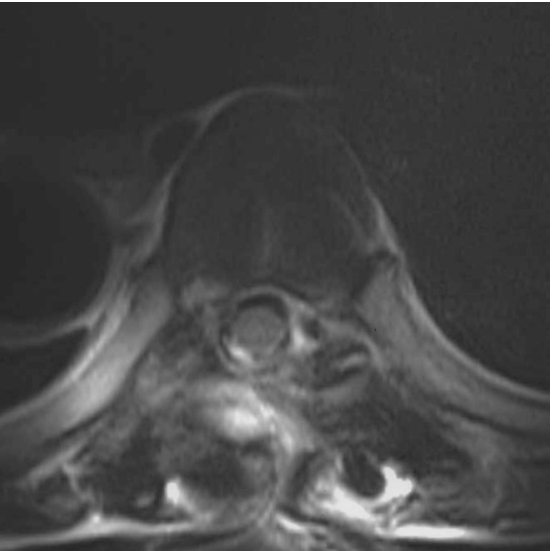

(b)

Figure 5. Thoracic spine MRI after operation. As of one year after surgery, no recurrence has been observed on MRI. (a) Sagittal T2 WI; (b) Axial T2 WI.

lesions [2]. However, purely epidural cavernous hemangiomas are rare, and, to our knowledge, only 24 cases have been reported in Japan [3]-[21]. In other countries, 99 cases have been reported [1] [2] [22]-[64], and 55 [3]-[29] [32] [35]-[38] [41] [45] [46] [52] [55] [60] were reported from Asian countries. When the Japanese cases 
were investigated, the mean age was 53.7 years old ( 7 - 80 years old), and the male: female ratio was 7:4; showing that the incidence tends to be higher in men. The development site was the cervical spinal cord in $2(8 \%)$, the cervicothoracic spinal cord in $3(13 \%)$, the thoracic spinal cord in $13(54 \%)$, the thoracolumbar spinal cord in 2 $(8 \%)$, the lumbar spinal cord in $2(8 \%)$, and unclear in $2(8 \%)$; thus, development from the thoracic spinal cord accounted for more than half of such cases $(54 \%)$. The initial symptoms have been diverse, including myelopathy, radiculopathy, and local pain [1], in $12(50 \%), 8(33 \%), 3(13 \%)$ of the Japanese cases, respectively, and unclear in $1(4 \%)$. In our patient, the initial symptom was myelopathy. With respect to the pattern of development, when the time to surgery after onset was divided into acute ( $<1$ month), subacute $(1-6$ months), and chronic (6 months or later), the development was acute, subacute, and chronic in $4(17 \%), 3(13 \%)$, and 11 $(46 \%)$, respectively, and was unclear in $6(25 \%)$. Three chronic cases that became acutely aggravated were treated with emergency surgery.

Among the imaging findings for this disease, Padovani et al. [51] and Kurose et al. [18] have reported dilation of the intervertebral foramen on plain radiography; however, this was not observed in our patient. Furthermore, dilation of the intervertebral foramen on plain radiography has been described as not being characteristic of epidural cavernous hemangioma in many reports.

On myelography, exclusion of the dural canal was observed, but this is also a general finding of epidural tumors that is not specific to this disease.

Iso-low- and high-intensity regions are generally observed on T1- and T2-weighted imaging, respectively, and enhancement is observed on gadolinium contrast imaging [3] [4]; however, these findings are also not specific to this disease.

With respect to the clinical diagnosis, there are no characteristic physical or imaging findings, and the tumor could be diagnosed as schwannoma, epidural hematoma, and epidural abscess, excluding cases that were pathologically diagnosed before surgery using VATS. Thus, it is difficult to make a definitive diagnosis before surgery due to the low incidence and the absence of characteristic imaging findings.

For treatment, surgery is generally selected [3] [7] [51]. While one conservatively-treated case has been reported in another country, the outcome was poor [3]. All Japanese cases were treated with tumor resection under decompression. In our patient, since the tumor was not diagnosed before surgery, we selected tumorectomy combining facetectomy and fixation to safely allow observation of the entire tumor. The postoperative course was favorable, with disappearance of the spinal cord symptoms and improvement of the gait disturbance.

It is difficult to preoperatively diagnose epidural cavernous hemangiomas, because there are no characteristic clinical symptoms or imaging findings and the incidence low. When a tumor lesion is observed, it is important to suspect epidural cavernous hemangioma in the differential diagnosis of epidural tumors before surgery.

\section{Conclusion}

We encountered a patient with spinal epidural cavernous hemangioma of the thoracic spine. There are very few reported cases of this disease, and its preoperative diagnosis is difficult. The disease could not be diagnosed before surgery in our patient. However, complete excision was performed and a favorable outcome was achieved.

\section{Consent}

Informed consent was obtained from the patient for publication of this case report.

\section{Conflicts of Interest}

The authors declare that they have no conflicts of interest with respect to the publication of this case report.

\section{References}

[1] Hillman, J. and Bynke, O. (1991) Solitary Extradural Cavernous Hemangiomas in the Spinal Canal. Surgical Neurolo$g y$, 36, 19-24. http://dx.doi.org/10.1016/0090-3019(91)90127-u

[2] Wyburn-Mason, R. (1943) Vascular Abnormalities and Tumors of the Spinal Cord and Its Membranes. Kimpton, London, 24-95.

[3] Aoyagi, N., Kojima, K. and Kasai, H. (2003) Review of Spinal Epidural Cavernous Hemangioma. Neurologia Medico-chirurgica, 43, 471-476. http://dx.doi.org/10.2176/nmc.43.471 
[4] Hara, K. and Hidaka, K. (2006) Cavernous Hemangioma Growing Continuously from the Spinal Epidural Space into the Paravertebral Muscles: Case Report. No Shinkei Geka, 34, 521-525.

[5] Kuroiwa, M., Yamamoto, Y., Watanabe, M. and Mochida, J. (2012) Extradural Cavernous Hemangioma at Lumbar Spine: A Case Report. Kanto-Seikei-saigaigekagakkaisi, 43, 412-415. (In Japanese)

[6] Hachinoda, J., Yasuda, T., Hori, T., Suzuki, K., Kawaguchi, Y. and Kanamori, M. (2012) Epidural Cavernous Hemangioma Arising from Cervicothoracic Spine: Report of a Case. Seikeigeka, 63, 329-332. (In Japanese)

[7] Ban, M., Akune, H., Mori, T., Takahashi, Y., Imamura, R., Yano, H., Nakamura, T., Saita, Y., Inoue, S., Suenaga, K., Kikuchi, N., Kozuma, M. and Kawano, N. (2011) A Case of Spinal Epidural Cavernous Hemangioma of the Thoracic Spine. Seikeigeka and Saigaigeka, 60, 278-282. (In Japanese)

[8] Shimokawa, N. and Fu, Y. (2008) A Case of Epidural Cavernous Hemangioma in Cervicothoracic Spine. The Journal of the Medical Society of Spinal Cord Lesion, 21, 88-89. (In Japanese)

[9] Uchida, K., Yayama, T., Nakajima, H., Hirai, T., Kobayashi, S., Chen, K., Guerrero, A.R. and Baba, H. (2010) Microsurgical Resection of Cavernous Haemangioma around the Thoracic Neuroforamen: A Case Report. Journal of Orthopaedic Surgery, 18, 370-373.

[10] Anzai, K., Senoo, M., Mizobuchi, M. and Nakamura, H. (2003) A Case of Thoracic Epidural Cavernous Angioma. Journal of Neurosurgery, 12, 508-512. (In Japanese)

[11] Asaumi, K., Takei, Y. and Kadota, H. (2002) A Case of Dumbbell-Shaped Spinal Epidural Cavernous Hemangioma. Chugoku-Shikoku Seikeigeka Gakkaisi, 14, 181-185. (In Japanese)

[12] Muroi, A., Akira, M., Hiroyuki, A., et al. (2001) Spinal Extradural Cavernous Hemangioma. Spinal Cord Surgery, 15, 201. (In Japanese)

[13] Kitahara, J., Yasukawa, Y., Akizuki, A., Takizawa, T. and Kobayashi, H. (2000) A Case Report of Extradural Cavernous Hemangioma in Lumbar Spine Which Had Difficulty in Diagnosis before Surgery. Rinsho-Seikeigeka, 35, 813-815. (In Japanese)

[14] Suga, T., Murakami, E., Ishizuka, M., Fang, S.N., Yoshioka, K. and Sano, M. (1996) A Case of Acromegaly Associated with Variegated Spinal Disorders. No Shinkei Geka, 24, 927-932

[15] Inoue, T., Koga, H., Abe, M. and Tabuchi, K. (1995) Solitary Spinal Epidural Cavernous Haemangioma Presenting as Acute Epidural Haematoma. Journal of Clinical Neuroscience, 2, 265-268. http://dx.doi.org/10.1016/s0967-5868(95)80013-1

[16] Uchibori, M., Imahori, Y., Mizukawa, N. and Ueda, S. (1990) A Case of Cervical Epidural Cavernous Angioma Mimicking a Disc Herniation. Sekitui-Sekizui Journal, 3, 631-636. (In Japanese)

[17] Satoh, T., Yamakawa, H., Oka, T., Suzuki, M., Watanabe, T., Tajima, T., Toba, Y. and Asahina, S. (1990) A Case of Thoracic Epidural Cavernous Hemangioma with Vast Vascular Nevi. Seikeigeka, 41, 755-758. (In Japanese)

[18] Kurose, K., Kishi, H. and Sadatoh, T. (1989) Spinal Epidural Cavernous Hemangioma. Case Report. Neurologia Medico-Chirurgica, 29, 538-542. http://dx.doi.org/10.2176/nmc.29.538

[19] Fukushima, M., Nabeshima, Y., Shimazaki, K. and Hirohata, K. (1987) Dumbbell-Shaped Spinal Extradural Hemangioma. Archives of Orthopaedic and Traumatic Surgery, 106, 394-396. http://dx.doi.org/10.1007/BF00456877

[20] Ogawa, T., Kikuchi, T., Ikeuchi, S., Sanada, S., Nakajima, T. and Anno, I. (1986) CT Findings in Acute Spinal Epidural Hematoma Caused by a Ruptured Cavernous Angioma. No Shinkei Geka, 14, 687-691.

[21] Morioka, T., Nakagaki, H., Matsushima, T. and Hasuo, K. (1986) Dumbbell-Shaped Spinal Epidural Cavernous Angioma. Surgical Neurology, 25, 142-144. http://dx.doi.org/10.1016/0090-3019(86)90282-X

[22] Yaldiz, C., Asil, K., Ceylan, D. and Erdem, S. (2015) Thoracic Extraosseous Epidural Cavernous Hemangioma. Journal of Korean Neurosurgical Society, 57, 65-67. http://dx.doi.org/10.3340/jkns.2015.57.1.65

[23] Li, T.Y., Xu, Y.L., Yang, J., Wang, J. and Wang, G.H. (2015) Primary Spinal Epidural Cavernous Hemangioma: Clinical Features and Surgical Outcome in 14 Cases. Journal of Neurosurgery: Spine, 22, 39-46. http://dx.doi.org/10.3171/2014.9.SPINE13901

[24] Jang, D., Kim, C., Lee, S.J., Ryu, Y.J. and Kim, J. (2014) Pure Spinal Epidural Cavernous Hemangioma with Intralesional Hemorrhage: A Rare Cause of Thoracic Myelopathy. Korean Journal of Spine, 11, 85-88. http://dx.doi.org/10.14245/kjs.2014.11.2.85

[25] Sharma, M.S., Borkar, S.A., Kumar, A., Sharma, M.C., Sharma, B.S. and Mahapatra, A.K. (2013) Thoracic Extraosseous, Epidural, Cavernous Hemangioma: Case Report and Review of Literature. Journal of Neurosciences in Rural Practice, 4, 309-312. http://dx.doi.org/10.4103/0976-3147.118772

[26] Hemalatha, A.L., Ravikumar, T., Chamarthy, N.P. and Puri, K. (2013) A Pure Epidural Spinal Cavernous Hemangioma-With an Innocuous Face but a Perilous Behavior!! Journal of Clinical and Diagnostic Research, 7, 1434-1435. 
[27] Rahman, A., Hoque, S.U., Bhandari, P.B. and Abu Obaida, A.S. (2012) Spinal Extradural Cavernous Haemangioma in an Elderly Man. BMJ Case Reports, 2012, bcr2012006453. http://dx.doi.org/10.1136/bcr-2012-006453

[28] Zhong, W.Y., Huang, S.Q., Chen, H.F., Sun, H., Cai, B.W., Liu, Y. and You, C. (2012) Pure Spinal Epidural Cavernous Hemangioma. Acta Neurochirurgica, 154, 739-745. http://dx.doi.org/10.1007/s00701-012-1295-3

[29] Sanghvi, D., Munshi, M., Kulkarni, B. and Kumar, A. (2010) Dorsal Spinal Epidural Cavernous Hemangioma. Journal of Craniovertebral Junction and Spine, 1, 122-125. http://dx.doi.org/10.4103/0974-8237.77677

[30] Floeth, F., Riemenschneider, M. and Herdmann, J. (2010) Intralesional Hemorrhage and Thrombosis without Rupture in a Pure Spinal Epidural Cavernous Angioma: A Rare Cause of Acute Lumbal Radiculopathy. European Spine Journal, 19, S193-S196. http://dx.doi.org/10.1007/s00586-010-1345-6

[31] Sarikaya-Seiwert, S., Gierga, K., Wessalowski, R., Steigner, H.J. and Hänggi, D. (2010) Solitary Spinal Epidural Cavernous Angiomas in Children Presenting with Acute Neurological Symptoms Caused by Hemorrahage. Journal of Neurosurgery: Pediatrics, 5, 89-93. http://dx.doi.org/10.3171/2009.7.PEDS09203

[32] Satpathy, D.K., Das, S. and Das, B.S. (2009) Spinal Epidural Cavernous Hemangioma with Myelopathy: A Rare Lesion. Neurology India, 57, 88-90. http://dx.doi.org/10.4103/0028-3886.48805

[33] Iglesias, S., Ayerbe, J., Sarasa, J.L., Sousa, P., Torres, C. and Ruiz-Barnés, P. (2008) Dumbbell-Shaped Spinal Epidural Cavernous Angioma. Case Report and Review of the Literature. Neurocirugia, 19, 248-253. http://dx.doi.org/10.1016/S1130-1473(08)70228-8

[34] Marshman, L.A., David, K.M. and Chawda, S.J. (2007) Lumber Extradural Arteriovenous Malformation: Case Report and Literature Review. The Spine Journal, 7, 374-379. http://dx.doi.org/10.1016/j.spinee.2006.03.013

[35] Jo, B.J., Lee, S.H., Chung, S.E., Paeng, S.S., Kim, H.S., Yoon, S.W. and Yu, J.S. (2006) Pure Epidural Cavernous Hemangioma of the Cervical Spine That Presented with an Acute Sensory Deficit Caused by Hemorrhage. Yonsei Medical Journal, 47, 877-880. http://dx.doi.org/10.3349/ymj.2006.47.6.877

[36] Hatiboglu, M.A., Iplikcioglu, A.C. and Ozcan, D. (2006) Epidural Spinal Cavernous Hemangioma. Neurologia Medico-Chirurgica, 46, 455-458. http://dx.doi.org/10.2176/nmc.46.455

[37] Minh, N.H. (2005) Cervicothoracic Spinal Epidural Cavernous Hemangioma: Case Report and Revier of the Literature. Surgical Neurology, 64, 83-85. http://dx.doi.org/10.1016/j.surneu.2004.10.030

[38] Cheng, L.T. and Lim, W.E. (2005) Spinal Epidural Haemangioma Associated with Extensive Gastrointestinal Haemangiomas. A Case Report. Interventional Neuroradiology, 11, 161-166.

[39] Nagi, S., Megdiche, H., Bouzaïdi, K., Haouet, S., Khouja, N., Douira, W., Sebaï, R., Chaabene, S., Zitouna, M. and Touibi, S. (2004) Imaging of Spinal Epidural Cavernous Malformations. Journal of Neuroradiology, 31, 208-213. http://dx.doi.org/10.1016/S0150-9861(04)96993-3

[40] D’Andrea, G., Ramundo, O.E., Trillò, G., Roperto, R., Isidori, A. and Ferrante, L. (2003) Dorsal Foramenalextraosseous Epidural Cavernous Hemangioma. Neurosurgical Review, 26, 292-296.

[41] Goyal, A., Singh, A.K., Gupta, V. and Tatke, M. (2002) Spinal Epidural Cavernous Haemangioma: A Case Report and Review of Literature. Spinal Cord, 40, 200-202. http://dx.doi.org/10.1038/sj.sc.3101248

[42] Saringer, W. (2001) Extraforaminal, Thoracic, Epidural Cavernous Haemangioma: Case Report with Analysis of Magnetic Resonance Imaging Characteristics and Revier of the Literature. Acta Neurochirurgica, 143, 1293-1297. http://dx.doi.org/10.1007/s007010100028

[43] Félix, A., Koerbel, A., Hanel, R.A., Cichon, E. and Araujo, J.C. (2001) Extradural Spinal Cavernous Haemangioma: Case Report and Review of the Literature. Arquivos de Neuro-Psiquiatria, 59, 440-443. http://dx.doi.org/10.1590/S0004-282X2001000300025

[44] Appiah, G.A., Knuckey, N.W. and Robbins, P.D. (2001) Extradural Spinal Cavernous Haemangioma: Case Report and Review of the Literature. Journal of Clinical Neuroscience, 8, 176-179. http://dx.doi.org/10.1054/jocn.2000.0756

[45] Shin, J.H., Lee, H.K., Rhim, S.C., Park, S.H., Choi, C.G. and Suh, D.C. (2001) Spinal Epidural Cavernous Hemangioma: MR Findings. Journal of Computer Assisted Tomography, 25, 257-261. http://dx.doi.org/10.1097/00004728-200103000-00019

[46] Daneyemez, M., Sirin, S. and Duz, B. (2000) Spinal Epidural Cavernous Angioma: Case Report. Minimally Invasive Neurosurgery, 43, 159-162. http://dx.doi.org/10.1055/s-2000-8336

[47] Carlier, R., Engerand, S., Lamer, S., Vallee, C., Bussel, B. and Polivka, M. (1999) Foraminal Epidural Extra Osseous Cavernous Hemangioma of the Cervical Spine: A Case Report. Spine, 25, 225-235.

[48] Talacchi, A., Spinnato, S., Alessandrini, F., Iuzzolino, P. and Bricolo, A. (1999) Radiologic and Surgical Aspects of Pure Spinal Epidural Cavernous Angiomas. Report on 5 Cases and Review of the Literature. Surgical Neurology, 52, 198-203. http://dx.doi.org/10.1016/S0090-3019(99)00064-6

[49] Padolecchia, R. (1998) Epidural Spinal Cavernous Hemangioma. Spine, 23, 1136-1140. 
http://dx.doi.org/10.1097/00007632-199805150-00013

[50] Zevgaridis, D., Büttner, A., Weis, S., Hamburger, C. and Reulen, H.J. (1998) Spinal Epidural Cavernous Hemangiomas. Report of Three Cases and Review of the Literature. Journal of Neurosurgery, 88, 903-908. http://dx.doi.org/10.3171/jns.1998.88.5.0903

[51] Padovani, R. (1997) Cavernous Angiomas of the Spinal District: Surgical Treatment of 11 Patients. European Spine Journal, 6, 298-303. http://dx.doi.org/10.1007/BF01142674

[52] Bavbek, M., Yurt, A., Caner, H. and Altinörs, N. (1997) An Unusual Dumbbell Form of Cavernous Hemangioma of the Cervical Spine. Kobe Journal of Medical Sciences, 43, 57-63.

[53] Yettou, H., Vinikoff, L., Baylac, F. and Marchal, J.C. (1996) Spinal Epidural Cavernous Angioma. Apropos of 2 Cases. Review of the Literature. Neurochirurgie, 42, 300-304.

[54] Faleh-Tamimi, A. and Tamimi, S.O. (1995) Extensive Epidural Hemangioma with Skin and Bone Involvement. A Case Report. Spine, 20, 2470-2472. http://dx.doi.org/10.1097/00007632-199511001-00018

[55] Harrington Jr., J.F., Khan, A. and Grunnet, M. (1995) Spinal Epidural Cavernous Angioma Presenting as a Lumbar Radiculopathy with Analysis of Magnetic Resonance Imaging Characteristics: Case Report. Neurosurgery, 36, 581584. http://dx.doi.org/10.1227/00006123-199503000-00018

[56] Lanotte, M., Massaro, F., Faccani, G., Forni, M. and Valentini, M.C. (1994) Dumbbell-Shaped Spinal Epidural Cavernous Angioma. Case Report. The Italian Journal of Neurological Sciences, 15, 429-432. http://dx.doi.org/10.1007/BF02339907

[57] Isla, A. (1993) Spinal Epidural Hemangiomas. Journal of Neurosurgical Sciences, 37, 39-42.

[58] Haimes, A.B. and Krol, G. (1991) Dumbbell-Shaped Spinal Cavernous Hemangioma: A Case Report. American Journal of Neuroradiology, 12, 1021-1022.

[59] Morello, A., Tumbiolo, A., Pinto, G. and Lo Duca, B. (1991) Cavernous Angioma of the Spinal Dura. Journal of Neurosurgical Sciences, 35, 31-35.

[60] Lee, J.P., Wang, A.D., Wai, Y.Y. and Ho, Y.S. (1990) Spinal Extradural Cavernous Hemangioma. Surgical Neurology, 34, 345-351. http://dx.doi.org/10.1016/0090-3019(90)90013-F

[61] Franz, K., Lesoin, F., Leys, D., Krivosic, I. and Jomin, M. (1987) Spinal Epidural Dumbbell-Shaped Cavernous Angioma. Revue Neurologique, 143, 298-300.

[62] Ojeda, V.J. and Arandia, E.G. (1983) Primary Extradural Neoplasms Causing Spinal Cord Compression. Australian and New Zealand Journal of Surgery, 53, 77-83. http://dx.doi.org/10.1111/j.1445-2197.1983.tb02401.x

[63] Richardson, R.R. and Cerullo, L.J. (1979) Spinal Epidural Cavernous Hemangioma. Surgical Neurology, 12, $266-268$.

[64] Lechevalier, B., Derlon, J.M., Houtteville, J.P., Théron, J. and Prévot, P. (1979) Associated Vertebral Angioma and Epidural Cavernoma. Revue Neurologique, 135, 237-244. 